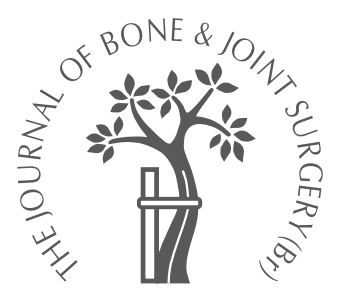

D. M. Niall, R. W. Nutton, J. F. Keating

From the Royal

Infirmary of

Edinburgh,

Edinburgh, Scotland

D. M. Niall, FRCS(Orth),

Knee Fellow

R. W. Nutton, FRCS

Consultant Orthopaedic

Surgeon

J. F. Keating, FRCS Ed

(Orth), Consultant

Orthopaedic Surgeon

Department of Orthopaedic

Surgery, Royal Infirmary,

Little France, Old Dalkeith

Road, Edinburgh EH16 4SU,

UK.

Correspondence should be sent to Mr J. F. Keating;

e-mail:

johnkeating@ed.ac.uk

(C)2005 British Editorial

Society of Bone and

Joint Surgery

doi:10.1302/0301-620X.87B5

$15607 \$ 2.00$

$J$ Bone Joint Surg $[\mathrm{Br}]$

2005;87-B:664-7.

Received 29 April 2004;

Accepted after revision

8 September 2004

\title{
Palsy of the common peroneal nerve after traumatic dislocation of the knee
}

Injury to the common peroneal nerve was present in 14 of 55 patients $(25 \%)$ with dislocation of the knee. All underwent ligament reconstruction. The most common presenting direction of the dislocation was anterior or anteromedial with associated disruption of both cruciate ligaments and the posterolateral structures of the knee. Palsy of the common peroneal nerve was present in 14 of $34(41 \%)$ of these patients. Complete rupture of the nerve was seen in four patients and a lesion in continuity in ten.

Three patients with lesions in continuity, but with less than $7 \mathrm{~cm}$ of the nerve involved, had complete recovery within six to 18 months. In the remaining seven with more extensive lesions, two regained no motor function, and one had only MRC grade-2 function. Four patients regained some weak dorsiflexion or eversion (MRC grade 3 or 4). Some sensory recovery occurred in all seven of these patients, but was incomplete. In summary, complete recovery occurred in three $(21 \%)$ and partial recovery of useful motor function in four $(29 \%)$. In the other seven $(50 \%)$ no useful motor or sensory function returned.

Traumatic dislocation of the knee is uncommon and normally associated with high-energy injuries in sports or motor-vehicle accidents. ${ }^{1-5}$ The risk of vascular damage in association with dislocation of the knee is well known. Injury to the common peroneal nerve has also been reported with an incidence varying between $25 \%$ and $40 \% .^{1-3,6,7}$ The prognosis for recovery is considered to be poor ${ }^{1-3,6-10}$ but there have been few studies on the extent of nerve injury, the pattern of associated ligament injury and the exact prognosis for recovery. Our aim, therefore, was to define these patterns, the extent of injury to the nerve and the prognosis.

\section{Patients and Methods}

Between 1994 and 2001, we treated 55 patients with traumatic dislocation of the knee. Fourteen had palsy of the peroneal nerve at the time of presentation. Of these, seven had a persistent dislocation which was reduced under sedation; on presentation six were anterior or anteromedial dislocations and one was posterior. In the remaining seven patients, the dislocation was reduced before presentation. All patients underwent surgical reconstruction of the ligamentous injury and were followed prospectively for a minimum of 18 months.

The mean age at the time of injury was 30 years (19 to 65$)$. The dislocation was a result of a sporting injury in ten patients, a fall from a height in two, a motor-vehicle accident in one and an industrial accident in one. The injury was isolated in 13 cases. A 19-year-old man had bilateral dislocations, of which one was associated with palsy of the common peroneal nerve and was included in the study.

Three patients suspected of having an arterial injury had angiography, which was positive in two. An intimal tear in one was not associated with ischaemia and was treated non-operatively. Of the 14 patients, one, a 65 year-old woman (case 11), had a complete rupture of the popliteal artery with posterior dislocation of the knee. The arterial injury was repaired and the posterolateral corner was reconstructed at the same procedure. The posterior cruciate ligament (PCL) was also disrupted, but was not reconstructed. The remaining 13 patients underwent complete reconstruction of the ligamentous injury. In ten, this was performed within four days of injury while three had a delayed reconstruction. Three patients had pre-operative MRI to aid surgical planning. At the time of ligamentous reconstruction the surgical pathology and extent of the injury to the common peroneal nerve were defined both by examination under anaesthesia and the subsequent findings at exploration. Post-operative rehabilitation included a hinged brace for six to 12 weeks, de- 
Table I. Details of the 14 patients and recovery of the peroneal nerve

\begin{tabular}{|c|c|c|c|c|c|c|c|c|c|c|}
\hline \multirow[b]{2}{*}{ Case } & \multirow[b]{2}{*}{ Age (yrs) } & \multirow[b]{2}{*}{ Gender } & \multirow[b]{2}{*}{ Common peroneal nerve } & \multirow[b]{2}{*}{ EMG/NCS* } & \multicolumn{4}{|c|}{ MRC $^{11}$ muscle grade } & \multirow[b]{2}{*}{ Feeling } & \multirow[b]{2}{*}{ Nerve recovery } \\
\hline & & & & & TA & EHL & EDL & Peronei & & \\
\hline 1 & 24 & $\mathrm{M}$ & Contusion $3 \mathrm{~cm}$ & No & 5 & 5 & 5 & 5 & Full & Complete \\
\hline 2 & 35 & $M$ & Contusion $5 \mathrm{~cm}$ & No & 5 & 5 & 5 & 5 & Full & Complete \\
\hline 3 & 26 & $M$ & Contusion $7 \mathrm{~cm}$ & No & 5 & 5 & 5 & 5 & Full & Complete \\
\hline $4 \ddagger$ & 35 & $\mathrm{M}$ & Rupture & No & 0 & 0 & 0 & 4 & Full & Partial \\
\hline 5 & 20 & $M$ & Contusion $8 \mathrm{~cm}$ & No & 4 & 2 & 4 & 4 & Full & Partial \\
\hline 6 & 30 & $M$ & Contusion $8 \mathrm{~cm}$ & Axonotmesis & 3 & 0 & 2 & 3 & Full & Partial \\
\hline 7 & 19 & $M$ & Contusion $>10 \mathrm{~cm}$ & Axonotmesis & 0 & 0 & 0 & 0 & Partial & Partial \\
\hline 8 & 19 & $\mathrm{~F}$ & Contusion $>10 \mathrm{~cm}$ & Axonotmesis & 0 & 0 & 0 & 3 & Partial & Partial \\
\hline 9 & 27 & $\mathrm{M}$ & Contusion $7 \mathrm{~cm}$ & No & 0 & 0 & 0 & 3 & Partial & Partial \\
\hline 10 & 19 & $M$ & Contusion $7 \mathrm{~cm}$ & Axonotmesis & 2 & 0 & 0 & 0 & Partial & Partial \\
\hline 11 & 65 & $\mathrm{~F}$ & Contusion $8 \mathrm{~cm}$ & Axonotmesis & 0 & 0 & 0 & 0 & Partial & Partial \\
\hline 12 & 27 & $M$ & Rupture & No & 0 & 0 & 0 & 0 & None & None \\
\hline 13 & 27 & $\mathrm{M}$ & Rupture & No & 0 & 0 & 0 & 0 & None & None \\
\hline 14 & 31 & $M$ & Rupture & No & 0 & 0 & 0 & 0 & None & None \\
\hline
\end{tabular}

* EMG/NCS, electromyography and nerve-conduction studies

† MRC, Medical Research Council muscle grade; TA, tibialis anterior; EHL, extensor hallucis longus; EDL, extensor digitorum longus

$\ddagger$ had sural graft at five months

pending on the nature of the ligamentous reconstruction, and a programme of accelerated rehabilitation. Patients were fitted with an ankle-foot orthosis and were advised to remain non-weight-bearing for six weeks after ligamentous reconstruction.

All of the patients were able to be reviewed for the purposes of the present study. The pre-operative and final MRC grade ${ }^{11}$ of muscle power was recorded and residual sensory loss was noted. The pattern of ligament disruption associated with injury to the common peroneal nerve was analysed and the subsequent treatment of the injury was documented.

\section{Results}

Thirteen of the 14 patients had clinical signs of complete palsy of the common peroneal nerve on presentation (Table I). One (case 10) had grade 2 power of tibialis anterior on presentation and was classified as an incomplete injury. In the remaining patients there was complete loss of motor function involving the anterior and peroneal compartment muscles with an associated sensory deficit on the dorsum of the foot. Three patients had MRI before surgery which identified injury to the anterior cruciate ligament (ACL), the PCL and/or the posterolateral corner and which was subsequently confirmed at surgery. The integrity of the common peroneal nerve could not be determined on standard MRI sagittal and coronal views.

At the time of surgical exploration, four patients (cases 4, 12, 13 and 14) were found to have complete rupture of the common peroneal nerve with proximal rupture of the nerve from the substance of the sciatic nerve. The damaged section of nerve extended from the sciatic nerve proximally to the neck of the fibula distally. The nerve was in continuity in the remaining ten patients. In these patients macroscopic evidence of injury to the nerve was present with attentuation, oedema, perineural haematoma and contusion. The damaged length of nerve was documented to be $7 \mathrm{~cm}$ or less in three patients (cases 1, 2 and 3) and between 7 and $12 \mathrm{~cm}$ in the remainder.

In all patients there was severe injury to the structures of the posterolateral corner including the tendons of popliteus and biceps femoris, the lateral collateral ligament and posterior capsule, and the arcuate and popliteofibular ligaments, with rupture or avulsion of the mid-substance. Eight patients had an associated rupture of the ACL and PCL. There were three complete nerve ruptures and one lesion in continuity in this group. Five patients had rupture of the ACL, the posterolateral corner and a grade II injury of the PCL. There was one complete rupture of the nerve and four lesions in continuity in this group. One elderly patient (case 11) had combined disruption of the PCL and the posterolateral corner with a lesion in continuity. The medial collateral ligament was intact in all cases.

Lesions of the nerve in continuity (ten patients) were treated by observation. Complete recovery was observed in the three patients with a zone of nerve injury of $7 \mathrm{~cm}$ or less. In all three, a positive Tinel sign distal to the fibular head and objective signs of early recovery of the nerve were noted clinically by three months. Complete reccovery occurred in two patients at between three and six months. The third patient achieved full functional recovery by 16 months.

In the remaining seven patients, two (cases 7 and 11) had no motor recovery. These two patients had evidence of damage to the nerve extending over a distance of more than $7 \mathrm{~cm}$ (Table I). One patient (case 10) regained MRC grade 2 function in the tibialis anterior which was not of functional significance. Four (cases 5, 6, 8 and 9) were considered to have recovered useful function (MRC grade 3 or better in either the anterior or peroneal compartment). Recovery was slow and continued for 12 to 18 months. Nerve conduction and electromyographic (EMG) studies showed that the earliest signs of nerve regeneration occurred in the superficial branch of the peroneal nerve 
supplying the peroneal musculature. This muscle group was noted to recover more commonly than any of the muscles of the anterior compartment (Table I). The nerveconduction studies showed severe patterns of axonal degeneration with poor EMG responses. All seven patients in this group regained some sensory recovery. Full sensory recovery occurred in two patients and partial sensory recovery in five. Motor and sensory recovery was sufficient in two patients to allow a return to a normal range of sporting activity.

The four patients with complete rupture of the nerve had such an extensive lesion that any attempt at primary repair was considered to be futile. The damaged section of nerve was debrided back to macroscopically undamaged tissue. One patient with a complete rupture (case 4) underwent ipsilateral cable grafting of the sural nerve five months after the injury. This resulted in some restoration of motor recovery limited to the peroneal muscles (MRC grade 4) 18 months after surgery. Of the other three patients with complete rupture two underwent a tendon transfer of tibialis posterior. This restored a limited range of ankle dorsiflexion (MRC grade 4) to a neutral position and allowed both patients to discontinue use of an ankle-foot orthosis although the remaining patient continues to use a splint.

\section{Discussion}

Palsy of the common peroneal nerve was associated with dislocation of the knee in $25 \%$ of our series of 55 patients, exclusively with dislocations involving a disruption of the PCL and posterolateral corner. The incidence of palsy associated with this specific pattern was $41 \%$. Complete rupture of the nerve was most commonly found in dislocations with combined complete disruption of the ACL, PCL and posterolateral corner. The association of this specific pattern of injury with the highest risk of injury to the common peroneal nerve has not been reported before. Previous studies ${ }^{3,6,12,13}$ have not attempted to distinguish the incidence of injury to the peroneal nerve according to the direction of dislocation or pattern of rupture of the ligament although the overall incidence of nerve injury was similar to that in our study (Table II). Half of the patients had no useful recovery of the nerve; complete recovery of motor function occurred in $21 \%$ and partial recovery in $29 \%$.

The common peroneal nerve is susceptible to injury because of its fixed attachment in the region of the neck of the fibula. The nerve proximal to this location is vulnerable to a traction injury when the knee is subjected to varus and hyperextension forces. ${ }^{14-16}$ Distal to the fibula, the superficial branch runs vertically downwards in the substance of peroneus longus while the deep branch continues forwards horizontally between tibialis anterior and extensor digitorum longus where it is closely applied to the interosseous membrane. The deep branch may be more vulnerable to traction injury at the time of dislocation because of this latter relationship. ${ }^{14-16}$ In our study, the peroneal muscles, which are innervated by the superficial branch of the nerve,
Table II. Incidence of injury to and recovery of the common peroneal nerve with traumatic dislocation of the knee in the literature

\begin{tabular}{lcc}
\hline Authors & Incidence (\%) & Recovery (\%) \\
\hline Meyers et $\mathrm{al}^{4}$ & $14 / 53(26)$ & $2 / 14$ \\
Sisto and Warren $^{6}$ & $8 / 20(40)$ & $4 / 8$ \\
${\text { Werier et } \mathrm{al}^{12}}_{\text {Harner et al }}^{13}$ & $6 / 38(16)$ & $1 / 6$ \\
Total & $4 / 31(13)$ & $3 / 4$ \\
\hline
\end{tabular}

had a better prognosis for recovery than those of the anterior compartment which are supplied by the deep peroneal branch.

The prognosis for complete recovery of the nerve is poor and was found in only $21 \%$ of our patients. Previous studies have not reported on the prognosis in detail $3,6,12,13$ (Table II). We found that the best outlook was in lesions in continuity with a length of involvement of the nerve of $7 \mathrm{~cm}$ or less and which had a short conduction block and muscle activity on nerve-conduction and EMG studies.

The treatment of the nerve injury is difficult. Primary end-to-end repair is not technically feasible in complete ruptures because of extensive fraying involving a considerable portion of the damaged ends. There may be a role for grafting the nerve in these cases at the time of the acute ligamentous reconstruction, although we have no experience of this. Patients who regain no useful recovery can be considered for delayed nerve grafting or transfer of the tendon of tibialis posterior. In a recent large study of injury to the peroneal nerve from a variety of causes, the results of nerve grafting were poor when grafts in excess of $6 \mathrm{~cm}$ were required. ${ }^{17}$ This suggests that even primary grafting in our patients would have been associated with a poor prognosis because of the extent of involvement of the nerve. Secondary nerve grafting for traction injury of the peroneal nerve has been reported. ${ }^{17-20}$ Partial motor and sensory recovery of $35 \%$ to $50 \%$ may be expected but full restoration of function is rare.

Transfer of the tendon of tibialis posterior to restore active dorsiflexion is the alternative reconstructive procedure. $^{21,22}$ Mizel et al ${ }^{22}$ described anterior transfer of the posterior tibial tendon to the midfoot in ten patients with traumatic palsy of the peroneal nerve, with excellent results at six years. It is worth noting that acquired flatfoot and valgus hindfoot deformities do not tend to occur when complete transfer is performed in this situation. It has been suggested that this is probably because of the lack of normal function of the peroneal muscle ${ }^{20}$ which occurs with complete lesions of the common peroneal nerve.

No benefits in any form have been received or will be received from a commercial party related directly or indirectly to the subject of this article.

\section{References}

1. Kennedy JC. Complete dislocation of the knee joint. J Bone Joint Surg [Am] 1963; 45-A:889-904.

2. Shields L, Mital M, Cave EF. Complete dislocation of the knee: experience at the Massachusetts General Hospital. J Trauma 1969;9:192-215.

THE JOURNAL OF BONE AND JOINT SURGERY 
3. Meyers MH, Harvey JP Jr. Traumatic dislocation of the knee joint: a study of eighteen cases. J Bone Joint Surg [Am] 1971;53-A:16-29.

4. Meyers MH, Moore TM, Harvey JP Jr. Traumatic dislocation of the knee joint J Bone Joint Surg [Am] 1975;57-A:430-3.

5. Shelbourne KD, Porter DA, Clingman JA, McCarroll JR, Rettig AC. Low velocity knee dislocation. Orthop Rev 1991;20:995-1004.

6. Sisto DJ, Warren RF. Complete knee dislocation: a follow-up study of operative treatment. Clin Orthop 1985;198:94-101.

7. Taylor AR, Arden GP, Rainey MA. Traumatic dislocations of the knee: a report of forty-three cases with special reference to conservative treatment. J Bone Joint Surg [Br] 1972:54-B:96-102

8. Jones RE, Smith EC, Bone GE. Vascular and orthopaedic complications of knee dislocation. Surg Gynecol Obstet 1979;149:554-8.

9. Montgomery TJ, Savoie FH, White JL, Roberts TS, Hughes JL. Orthopaedic management of knee dislocations: comparison of surgical reconstruction and immobilization. Am J Knee Surg 1995;8:97-103.

10. Windsor RE. Knee dislocation. In: Insall JN, Windsor RE, Scott WN, Kelly MA, Aglietti P, eds. Surgery of the knee. Second ed. New York: Churchill Livingstone, 1993 $555-9$

11. Magee DJ. Principles and concepts. In: Magee DJ, ed. Orthopaedic physical assess ment. Second ed. Philadelphia: W. B. Saunders Co., 1992;1-33.

12. Werier J, Keating JF, Meek RN. Complete dislocation of the knee: the long term results of ligamentous reconstruction. The Knee 1998:5:255-60
13. Harner CD, Waltrip RL, Bennett CH, et al. Surgical management of knee dislocations. J Bone Joint Surg [Am] 2004;86-A:262-3.

14. Deutsch A, Wyzykowski RJ, Victoroff BN. Evaluation of the anatomy of the common peroneal nerve: defining nerve-at-risk in arthroscopically assisted lateral meniscus repair. Am J Sports Med 1999:27:10-15.

15. Dellon AL, Ebmer J, Swier P. Anatomic variations related to decompression of the common peroneal nerve at the fibular head. Ann Plast Surg 2002;48:30-4

16. Ryan W, Mahony N, Delaney M, O'Brien M, Murray P. Relationship of the common peroneal nerve and its branches to the head and neck of the fibula. Clin Anat2003;16:501-5.

17. Kim DH, Murovic JA, Tiel RL, Kline DG. Management and outcomes in 318 operative common peroneal nerve lesions at the Louisiana State University Health Sciences Center. Neurosurgery 2004;54:1421-8.

18. Demuynck M, Zuker RM. The peroneal nerve: is repair worthwhile? J Reconst Microsurg 1987:3:193-7.

19. Sedel L, Nizard RS. Nerve grafting for traction injuries of the common peroneal nerve: a report of 17 cases. J Bone Joint Surg [Br] 1993;75-B:772-4.

20. Wilkinson MCP, Birch R. Repair of the common peroneal nerve. J Bone Joint Surg [Br] 1995:77-B:501-3.

21. Yeap JS, Birch $\mathbf{R}$, Singh D. Long-term results of tibialis posterior tendon transfer for drop-foot. Int Orthop 2001;25:114-8.

22. Mizel MS, Temple HT, Scranton PE Jr, et al. Role of the peroneal tendons in the production of the deformed foot with posterior tibial tendon deficiency. Foot Ankle Int 1999:20:285-9. 